\title{
Editorial
}

\section{Analysis of Climate Change Impacts on Water Resources For Developing Economies: Successes and Challenges}

\author{
Adebayo J. Adeloye \& Chandra S. P. Ojha
}

This special issue is aimed at providing examples of current research and other activities related to the assessment of the impacts of climate change on water resources in developing economies. The recent $4^{\text {th }}$ Assessment Report by the IPCC [1] has put to rest any lingering doubts that our climate is changing and that the changes are largely due to human activities. The impacts of climate change on water resources, such as lower rainfall and its associated runoff, disappearing rivers and natural lakes, increased evapotranspiration leading to higher irrigation water withdrawals, dwindling groundwater stocks, and increased temperature effects on water quality and pollution exacerbation, are being felt in both developed and developing economies [2]. In the other extreme are frequent flooding incidences that are causing untold hardship and misery to millions of people around the world.

However, the ability to analyse climate change related impacts and hence develop appropriate and effective mitigating and adaptation measures is limited in developing countries because of weak institutions, lack of long-term, time series observations on the hydrologic cycle, and other constraints [3]. The situation is not helped by the huge uncertainties that often characterise assessed impacts, even when all the underlying circumstances are conducive as recently demonstrated by Nawaz and Adeloye [4].

Contributions in this special issue, eight in all, have focused on the peculiar situations in developing countries by emphasising any successes recorded and the main challenges. Ghosh et al. presented the modelling techniques that normally underpin climate change water resources impacts assessment and warn that while some of these modelling paradigms are well established, there are some limitations when applying them, including uncertainties in general circulation models' (GCMs) predictions, especially when downscaled to the catchment scale, and the difficulty associated with any attempt to incorporate future demographic and land use changes in impacts assessment. They stressed that these problems are accentuated in developing countries because of their circumstances and they then went on to propose different, alternative approaches which have huge potential for resolving the problems.

Ojha et al. were concerned with downscaling precipitation, one of the most inaccurately predicted elements of the hydrological cycle by GCMs, to finer scale resolutions such as those required at the catchment scale. In the work, they considered the use of statistical downscaling approaches based on multiple regression and artificial neural networks (ANNs) paradigms. In the end, they found that when applied to the Pichola lake region in Rajasthan State of India, the ANN performed much better than their multiple regression formulations. ANNs have seen a resurging use in hydrology and water resources studies in recent times and are particularly useful for modelling non-linear relationships when the precise mathematical forms of such relationships are unknown or cannot be specified explicitly (see e.g. Adeloye [5]).

Nawaz et al. reported on the impact of climate change on the Blue Nile River in Africa. The study is a good example of the combined use of statistical spatiotemporal downscaling and an operational hydrological model for impacts assessment. Their methodology was applied to assess the sensitivity of upper Blue Nile flows at Diem flow gauging station to changes in future rainfall and evapotranspiration during the June-September rainy season based on output from three GCMs. The majority of the scenarios they investigated indicated wetter conditions, i.e. increased mean runoff, in the future. Impacts on extreme runoff were also examined, which indicated the possibility of more severe floods in the future. These are likely to be exacerbated by land-use changes including overgrazing, deforestation, and improper farming practices.

Lake Malawi was the subject of the work by Kumanbala and Ervine. The lake is the most strategic in Malawi by serving various purposes including hydropower generation, water supply for industrial and domestic use in the city of Blantyre and its surrounding urban areas, together with irrigation water in the Lower Shire Valley (LSV). Consequently, any changes in the hydrological or ecological behaviour of the lake will have far reaching consequences for the economy of Malawi. It is therefore no wonder that the lake has been intensively studied in the past but the main contribution of the current authors was to incorporate climate change modelling into the existing water balance model, so as to enable objective and more comprehensive assessment of the likely future behaviour of the lake. The results showed that water level in the lake will continue to drop because of decreasing rainfall and increasing evaporation. This situation calls for an urgent need to develop viable alternatives for both hydropower and irrigation development, since the current over-reliance on the lake's water may not be sustainable for the future.

Oyebande and Odunuga review the situations of three river basins in West Africa, namely Senegal, Niger and the Volta, all of which have witnessed significant droughts in recent years that have impacted on water resources availability, ecosystems 
services and the economies of the nations drained by the rivers. They document the challenges faced by attempts to objectively assess these impacts including regional demographic factors, inadequate or non-existing water policies, inefficient management strategies and most importantly, the lack of reliable and adequate data. Since these changes are already happening, however, the paper argues that it might be too late to be talking about mitigation but rather, the authors conclude with some recommendations on what could be done in terms of adaptation strategies to reduce the severity of the impacts on the stressed and largely poverty-stricken people within the basins.

Vithanage et al. investigation on the vulnerability analysis of coastal sandy aquifers in Sri Lanka to sea water intrusion and the impact which dwindling recharge caused by climate change could have on this is the only work in this compilation that has addressed groundwater issues directly. Groundwater, in the sand aquifer in between sea and lagoon configuration typically found in eastern Sri Lanka, is the only source of water for domestic as well as agricultural purposes in the region. The study estimated the safe yield of the aquifer and the effect of climate change and other factors on it using a modelling approach. While the results did not indicate groundwater mining or sea water intrusion under current conditions, the situation may change with the increase of population, increase of pumping, and reduction of recharge due to climate change.

Rai et al. presented different statistical tools for testing for persistence, trend and periodicity in time series data, all of which are necessary to establish whether or not climate change is causing shifts in the time series. Undoubtedly, there are so many reference textbooks that cover these subjects but by bringing them together is this comprehensive article, Rai et al. have provided a single and convenient reference source for hydrologists, water resources analysts and others with interests in the stochastic behaviours of hydrometeorological time series data.

The final article in the series is by Sharma et al. and concerns the assessment of failure risk from river bank erosion in the Brahmaputra river basin. Land losses to erosion have seen a significantly rising trend in recent years, which have contributed to the impoverishment of the riverine population who rely on its ecosystem services for their livelihoods. The hazard posed by unabated bank erosion was analysed with the help of satellite imagery based data and through adoption of Plan Form Index along with its threshold values developed for the Brahmaputra. It was argued that the attendant uncertainties of climate change on hydrological and hydraulic behaviours of the River may exacerbate the channel instability of the Brahmaputra, thus making the development of appropriate mitigation and adaptation management strategies difficult.

All in all, this Special Issue has lived up to its expectations and we would like to commend the articles to all researchers and practitioners with interests in developing countries' hydrology and water resources situations. The excellent compilation would not have been possible without the dedication and professionalism of the contributing authors. We would like to thank them immensely and to plead with the wider hydrological and water resources research communities that whenever any of the articles is cited, they should be attributed to the respective authors instead of simply citing the two of us, the guest editors. This special issue would also not have been possible without the assistance of those experts who carried out the reviews of the articles, sometimes under very difficult circumstances. We initially thought about mentioning people's names individually but on further thoughts and given the understanding they had with us that they would remain anonymous, we have decided against this. You do, however, know yourselves and you merit our deep sense of gratitude. Our final thanks go to the Publishers, Bentham, and the Editor-in-Chief of the Open Hydrology Journal for the invitation to undertake the guest-editorship of the Special Issue. We would like to assure them that it is something that we have really enjoyed and would be available to be of further real service to the Journal in the future.

\section{REFERENCES}

[1] IPCC, Climate Change, 2007: Impacts, Adaptation and Vulnerability. Contribution of Working Group II to the Fourth Assessment, Report of the Intergovernmental Panel on Climate Change, M.L. Parry, O.F. Canziani, J.P. Palutikof, P.J. van der Linden and C.E, Hanson, Eds., Cambridge University Press, Cambridge, UK, 976pp, 2007.

[2] The Royal Academy of Engineering, 2010: Global water security- an engineering perspective. The Royal Academy of Engineering, London, England.

[3] Adeloye, A. J. and Rustum, R., 2010: Lagos (Nigeria) flooding and influence of urban planning. Manuscript submitted to J. Urban design and planning, Proceedings ICE, (Revised version now submitted).

[4] Nawaz NR, Adeloye AJ. Monte Carlo assessment of sampling uncertainty of climate change impacts on water resources yield in Yorkshire, England. Climatic Change 2006, 78: 257-92.

[5] Adeloye AJ. Multiple linear regression and artificial neural networks model for generalised reservoir storage-yield-reliability function for reservoir planning. J Hydrol Eng 2009, 14(7), 731-8.

(C) Adeloye and Ojha; Licensee Bentham Open.

This is an open access article licensed under the terms of the Creative Commons Attribution Non-Commercial License (http://creativecommons.org/ licenses/by-nc/3.0/) which permits unrestricted, non-commercial use, distribution and reproduction in any medium, provided the work is properly cited. 